\title{
Disposition Effect and Induce Transaction in Future Market Based on Prospect Theory
}

\author{
Wenhui Li, Xing Yu and Hongguo Sun \\ Hunan University of Humanities, Science and Technology, Loudi, Hunan
}

\begin{abstract}
Futures brokers' income is mainly based on poundage, which easily lead to induce investors do unnecessary transactions. Disposition effect exist in future market commonly. We construct a prospect theory investment decision model with induce transaction, to explore the relationship between induce transactions and disposition effect. The results show that there is disposition effect and induce transaction in China's futures market. The investors are conducted by intermediaries and IB broker, who do more unnecessary transactions than the investors conduct by staff. Induced transaction not only accelerates the investors to realize winners, but also hold the losses longer, but the impact on the two is asymmetrical, which has a more significant impact on the winners. The relationship between the induced transaction and the disposal effect is not linear, appropriate induce transaction reduce disposition effect, but excessive will increase the disposition effect of the futures market.
\end{abstract} theory

Keywords-disposition effect; induce transaction; prospect

\section{INTRODUCTION}

Futures brokers are important carriers linking Futures Company and customers. Them are divided into three types: staff brokers, intermediaries and IB brokers. Different kinds of brokers have different basis to get earnings, staff brokers' earnings are based on investors' poundage and margin, but others two are just based on investors' poundage. In order to get higher earnings, the brokers will induce investors have unnecessary transactions. Meanwhile, most investors in China's futures market are not professional, especially for the small and medium retail, they didn't have enough professional knowledge and experience, and have limited access to get market information. Therefore, their investment decisions are vulnerable to external influences, especially the brokers' investment advices. So, the induce transaction will be take place more easily in China's future market.

The disposition effect is a typical irrational investment behavior in futures market, it indicates that investor realize winners too soon, but hold losses too long. Brokers is professionals, their investment advices are highly valued by investors, especially for the small retail. we can infer that investors' investment decision will be effect by the brokers. prospect theory account for investment decision-making, which did not consider the brokers' investment advice, we should add it. From analysis, we can see that effect of investment advice is asymmetrical.

Base on the above analysis, we will explore such problem: first different kinds of investors' disposition effect are different, who is conducted by different brokers. Second, we construct a new prospect theory model, which consider the brokers' advice. third we analysis the relationship between brokers' advice and disposition effect, according to the 10477 investors real trading data.

\section{RELATED RESEARCH}

The disposition effect is a typical irrational investment behavior, which exists in many countries' future markets. Many studies used the difference proportion between realize winners and hold looses to measure disposition effect. Used that method, Choe and $\operatorname{Eom}^{[5]}$ found that both individual and institution investors have disposition effect in Korean stock index futures market, Teng et al. ${ }^{[1]}$ found that individual investors have disposition effect in Taiwan futures market, Locke and Man ${ }^{[2]}$ found that the professional investors of the Chicago Mercantile Exchange also had disposition effect. But when we use this method, we should choose a reference price to Judge the winner and loss for each transaction. So many studies ${ }^{[4,5,6,9]}$ choose a weighted average price as reference price, but Deping Ren and $\mathrm{Xu}$ Gong ${ }^{[11]}$ think that the average price of 5 weeks is more suitable, xuli Chi and Xintian Zhuang ${ }^{[8]}$ think that different investors have different reference price in different market conditions. According the above analysis, the reference is determining factor, which one is more suitable, no agreement reached. To avoid this problem, we choose the yearly profit and loss condition to measure the disposition effect, no need to choose a reference price.

The disposition effect can be explained by the prospect theory. Yan and $\mathrm{Li}^{[3]}$ use the prospect theory, based on a general equilibrium model, to analyze the reason of disposition effect. But when they use prospect theory to explain the causes of the disposal effect, they didn't take the external factor. Investor valued investment advice from analysts and brokers. Hairong Zhou ${ }^{[12]}$, found that the analyst's investment proposals have important effect to the investment decisions, and increase the market volume obviously. Xiaozhou He, Wei Wen Jiang ${ }^{[13]}$ found that investors are very concerned about the broker's investment proposals, by a questionnaire survey. Mark and Randall ${ }^{[15]}$ also found that investors valued the brokers' investment advice great. Odean ${ }^{[16]}$ believes that investors are easily influenced by brokers' investment proposals when they making investment decisions. Yun hong Cai and Lin Ma ${ }^{[14]}$ found that the income based on poundage are likely to lead broker induced customer to do unnecessary transactions. But there is few explored the influence of broker induced trading on disposition effect from a quantitative perspective.

From the all above analysis, traditional prospect theory is not well described the investment decision, which is affected by the 
brokers' investment proposal. We construct a new investment decision-making model based on prospect theory, which take brokers' investment proposal as an external factor. Meanwhile, we use a large futures company as an example to explore the relationship.

\section{INVESTMENT DECISION-MAKING MODEL BASED ON PROSPECT THEORY}

\section{A. The Utility Function of Broker's Investment Advice}

The utility function of broker's investment advice is $\varphi(\mathrm{z}, \mathrm{k}), \mathrm{x}$ mean the benefit come from the proposal, $\mathrm{k}$ is number of proposal. We assume that broker is professional, their proposal is right in most time. The property of the utility function as follows.

When $\mathrm{z}>0, \varphi(\mathrm{z}, \mathrm{k})>0$ 。 It means that the proposal made the investor have earnings, the proposal is right, it brings a positive utility for the investor. Meanwhile, $\varphi(\mathrm{z}, \mathrm{k})$ is increasing function of $\mathrm{k}$, but it is decreasing function of $\mathrm{z}$. It means that, after many right proposals, investor will pay more attention to the proposal, but the positive utility of each increased profits is decrease progressively.

When $\mathrm{z}<0, \varphi(\mathrm{z}, \mathrm{k})<0$. It means that, the proposal made the investor loss, the proposal is wrong, it brings negative utility for the investor. But, $\varphi(\mathrm{z}, \mathrm{k})>\varphi(-\mathrm{z}, \mathrm{k})$. Mark and Randall ${ }^{[15]}$ find that, investors valued brokers' investment proposal, when investors make a profit by the proposal, the brokers' service get a better score (4.47 points, total 6 points), but when investor made a loss, the score is much lower (3.03 points).

\section{B. The New Prospect Theory}

If we add the utility function of broker's investment advice to prospect theory. The new utility function is $\mathrm{U}(\mathrm{x}, \mathrm{p}, \mathrm{y}, 1-$ $\mathrm{p}, \mathrm{z}, \mathrm{k})=\mathrm{V}(\mathrm{x}) \times \pi(\mathrm{p})+\mathrm{V}(\mathrm{y}) \times \pi(1-\mathrm{p})+\varphi(\mathrm{z}, \mathrm{k})$. When $\mathrm{x}>0 ; z>0$, and $\mathrm{x}$ is a better choice, so new utility function is that $\mathrm{V}(\mathrm{x}) \times \pi(\mathrm{p})+\varphi(\mathrm{z}, \mathrm{k}) \gg \mathrm{V}(\mathrm{y}) \times \pi(1-\mathrm{p})$, the investor will realize winners sooner, the profit not need to achieve $\mathrm{x}$. it means investment advice make investor realize winners sooner than before. When $\mathrm{x}<0 ; z<0$, investor like to hold loss, and $\mathrm{x}$ is a better choice, but brokers propose investor to realize loss, the new utility function maybe $\mathrm{V}(\mathrm{x}) \times \pi(\mathrm{p})+\varphi(\mathrm{z}, \mathrm{k})<$ $\mathrm{V}(\mathrm{y}) \times \pi(1-\mathrm{p})$, the investor may hold loss, when the loss achieve $\mathrm{x}$. it means investment advice make investor hold losses longer than before.

\section{DATA AND VARIABLES}

\section{A. Data}

The data is come from a large Futures Company in China, the company's margin ranked top 20 among 165 futures companies, classified supervision is A in 2013. There are 45000 investors, trade customers10795. We need two deals at least to judge their tendency, we delete the data, who just have one deal, the investor number become 10746. The proposal has greater effect on the small and medium investor. we delete the investor, whose future margin is more than 1 million investors, the number become 10477. In order to explore the relationship between proposal and disposition effect, 10, 477 investors are divided into 39 groups, in the order of daily margin size from large to small.

\section{B. Variables and Definition}

There are three groups of variables, including disposition effect, induce transaction and investor classification. Disposition effects can be measured by the number of accounts realize winners and hold losses. Induce transaction can be measured by the amount of poundage.

We Judge the profit and loss of the account by the actual yearly profit and loss, we need not to choose a reference price. That means realize winners and hold losses in the article are different, we need to de give a new definition about it. Realize winners is that: annual closed position for all of transaction is greater than zero.it means the investors like to realize winners. Hold losses is that: annual closed position for all of transaction is less than zero. It means the investors like to hold losses. Disposition effect(DE) is learn from Choe and Eom $^{[3]}$,The calculation method is as follows.

$$
\begin{gathered}
\text { PLR }=\frac{\text { holding losses }}{(\text { holding losses }+ \text { realize losses })} \\
\text { PGR }=\frac{\text { realize } \text { winners }}{(\text { realize } \text { winners }+ \text { hold winners })} \\
\mathrm{DE}=\mathrm{PGR}-\mathrm{PLR}
\end{gathered}
$$

PGR means proportion of gain realized, PLR means proportion of losses realized. If $\mathrm{DE}$ is bigger, that means, market is more irrational.

\section{EMPIRICAL ANALYSIS}

\section{A. Existence of Investment Proposals}

The income of employee brokers comes from two aspects, one is the scale of margin, the other is the scale of retention charge. The income of IB brokers and intermediator just comes from the scale of retention charge. So they valued retention charge much more, they will proposal his investors' do some unnecessary transaction. To prove this point, we count three kinds of broker' investors' transaction, respectively. The result is table I.

\section{TABLE I. COMPARISON OF INDUCEMENT TRANSACTIONS}

\begin{tabular}{|c|c|c|c|}
\hline Type & investor & volume & Retained fee \\
\hline employee & 6134 & 0.0150 & 0.056 \\
\hline Intermediator & 1734 & 0.0295 & 0.093 \\
\hline IB broker & 2878 & 0.0401 & 0.098 \\
\hline
\end{tabular}

We can see that the Intermediator and IB broker induce their investors made more transaction and get more retained fee. which proved that, there is induce transaction in china's future market, which is driven by interests.

\section{B. Relationship between Induce Transaction and the Number of Realize Winners and Hold Losses}

According to the prospect theory added induce transaction, we construct one dimensional linear regression model to explore the relationship, the result is table II. 
TABLE II. INDUCE TRANSACTION AND REALIZE WINNERS AND HOLD LOSSES

\begin{tabular}{|c|c|c|c|}
\hline & Coefficient & Probability & $\mathbf{R}$ \\
\hline hold winner & -59.53 & 0.008 & 0.52 \\
\hline hold losses & 69.86 & 0.007 & 0.56 \\
\hline realize winner & -78.95 & 0.007 & 0.37 \\
\hline realize losses & 89.29 & 0.009 & 0.46 \\
\hline
\end{tabular}

We can see that induce transaction made the number of hold loss and realize loss become more, but the number of hold winner and realize winner become less. contrast their coefficients, the realize loss or winner is bigger. It means the induce transaction have a much more effect on the realize the deal, But it have a less effect on hold losses or winners.

\section{Relationship between Induce Transaction and DE}

In order to explore the relationship between transaction and disposition effect, we also construction one dimensional linear regression model, the result is table VI. We can see that there is significant nonlinearity between disposal effects and induce transaction. Which is different from $\mathrm{CHO}$ and EO, they think that the more tradition the experience is more, so the DE is less. But this result tell us, the more tradition is not means more experience.

TABLE III. INDUCE TRANSACTION AND DE

\begin{tabular}{|c|c|c|c|c|}
\hline & Variable & Coefficient & Probability & \multirow{2}{*}{ R } \\
\hline \multirow{2}{*}{ DE } & Total Poundage & -1.39 & 0.007 & \multirow{2}{*}{0.5339} \\
\cline { 2 - 4 } & Total Poundage $\wedge 2$ & 1.08 & 0.008 & \\
\hline \multirow{2}{*}{ DE } & Retained Poundage & -1.57 & 0 & \multirow{2}{*}{0.59365} \\
\cline { 2 - 4 } & Retained Poundage $\wedge 2$ & 1.89 & 0.008 & \\
\hline
\end{tabular}

\section{CONCLUSION}

The brokers' commission is based on the retained fee, which make investor do some unnecessary transaction (induce transaction), that will affect the market efficiency. We construct a new prospect theory adding induce transaction and use the solid trading data of 10,746 investors in a large domestic futures company to do empirical analysis to explore the relation between induce transaction and disposition effect. The result is that if the induce transaction is moderate, which will decrease the disposition effect, but if the induce transaction is too much, which will increase disposition effect, the efficiency of future market will be lower. Taking one with another, the most of broker' induce transaction is moderate, but a small number of brokers' induce transaction is too much.

\section{REFERENCES}

[1] Teng, Lee and Chao,” An examination of the relationship between the disposition effect and gender, age, the traded security, and bull-bear market conditions” ,Journal of Empirical Finance, pp.195-213, January 2013.

[2] Locke and Mann, "Professional trader discipline and trade disposition", Journal of Financial Economics, Vol.76, pp.25-43, February2005.

[3] Choe and Eom, "The disposition effect and investment performance in the futures market”, Journal of Futures Markets, vol.29, pp.75-91, June 2005.

[4] Zhi Xu, xinyu Gan and jiagen Xu,” Research on the disposition effect of china’s futures market," Macroeconomic Research, pp.56-60, October 2013
[5] Zhi Xu, "Research on the behavior of individual investors in China futures market”, Southwest university of finance and Economics,2013.

[6] Shen Jun, "Behavior research of stock index futures investors based on behavioral finance," 2013. Southwest university of finance and Economics,2013.

[7] Kahneman and Tversky. "Prospect Theory: An Analysis of Decision under Risk”, Econometrica, pp. 263-291, February 19. 